\section{HIGH-VOLTAGE CIRCUIT-BREAKER TECHNIQUE}

$\mathrm{T}$ WO important papers were read in London before the Institution of Electrical Engineers on March 30 , one on restriking voltage as a factor in the performance, rating and selection of circuit-breakers, by Messrs. J. A. Harle and R. W. Wild, and the other on the influence of resistance switching on the design of high-voltage air-blast circuft-breakers, by Messrs. H. E. Cox and T. W. Wilcox.

In the first of these, Messrs. Harle and Wild point out that the behaviour of circuit-breakers when breaking short-circuit currents depends on a number of factors which include circuit power-factor, recovery voltage, earthing conditions, and current asymmetry. A further condition of severity is the restriking-voltage transient and its attribute, the rate of rise of restriking voltage. The paper shows the effect of this severity factor on the performance of plain-break oil circuitbreakers, oil circuit-breakers fitted with arc-control devices, and air-blast circuit-breakers. Compared with the relatively small effect that rate of rise has on plain-break and arc-control oil breakers, its importance for the performance of air-blast breakers is emphasized, and recommendations are made for its utilization in the rating, testing and selection of these breakers.

The conclusions reached may be summarized as follows. Plain-break oil circuit-breakers and oil circuit-breakers with arc-control contacts are relatively unaffected by the rate of rise of restriking voltage and hence the specification of its value is not essential, provided the circuit-breakers are tested in accordance with British Standard 116 under the severity conditions of the Association of Switchgear Testing Authorities. In air-blast circuit-breakers it is essential to take account of the rate of rise of restriking voltage when rating, testing and selecting, and in consequence they must be rated in terms of megavolt-amperes at a rated voltage and at a rate of rise of restriking voltage. Methods are proposed for specifying minimum rates of rise of restriking voltage for each megavolt-ampere rating and voltage, the adoption of which enables an economic range of switchgear to be designed which will meet all average conditions of severity in service and permit economic selection of circuit-breakers to be made.

A simple mothod of checking the suitability of any breaker rated as above for normal conditions of service is given, together with data for checking the suitability of any breaker for more unusual conditions of service. The method involves calculating the fault megavolt-amperes in the usual manner and checking that the proportion of the fault megavoltamperes contributed locally by generators, transformers, and the like, is not in excess of an amount appropriate to the breaker rating. Circuit-breakers rated in the manner advocated can also be selected for more severe conditions by adopting the methods described for reducing circuit severity in service. Proposals are made for testing air-blast circuitbreakers, including synthetic tests for certain types of high-voltage circuit-breakers the megavolt-ampere ratings of which are in excess of testing station outputs.

In the second paper, Messrs. Cox and Wilcox review the various problems which are met in designing highvoltage circuit-breakers, and the way in which the application of resistance switching confers another degree of freedom upon the designer in meeting the many conflicting requirements. It is first shown that a circuit-breaker must not only break its rated breaking current, but must- also limit the value of surge voltage which it causes while it is opening the circuit. This can be brought about by limiting the electric strength of the breaker contact gaps.

An experimental method of determining the electric strength of the nozzles under air-flow conditions is explained, followed by a discussion of the means by which resistance switching enables the designer to control both the nozzles independently. A $132-\mathrm{kV}$. breaker designed in conformity with the conclusions reached is described and test results are given for a full-scale test equipment. The paper then gives an analysis of the validity of 'unit testing' as applied to multi-break breakers with resistance switching, as compared with the use of the present two-part testing applied to oil circuit-breakers in accordance with British Standard 116, part 2. Finally, proposals are made for a series of type-test duties to be applied to air-blast circuit-breakers, in order to prove compliance with their breaking-capacity ratings.

The conclusions reached by Messrs. Cox and Wilcox are as follows. An air-blast circuit-breaker, like an oil circuit-breaker, causes over-voltages when it breaks a circuit under certain conditions. The prospective value of the over-voltage depends upon the circuit constants and upon the rate at which the arc is de-ionized. Under conditions very often realized in practice, the prospective value of such overvoltage can be dangerously high, and the actual value reached is limited only by restriking of the breaker gap. The latter thus not only has to be proportioned to break its rated breaking current, but also to limit, by restriking, the values reached by switching over-voltages. The breaker capacity and electric strength of a nozzle are interdependent, unless the restriking-voltage transient can also be controlled. The latter can be modified by means of resistance switching, so that by its introduction the breaking capacity and electric strength of the breaker can be controlled individually and independently.

By combining resistance switching with series multi-breaks, the distribution and exact shape of the restriking transient across each break can be controlled accurately. Thus 'unit testing' of such breakers is completely valid. This will greatly increase the scope of existing test plants for testing high-breakingcapasity breakers. The breaking-capacity type tests given in British Standard 116 for oil circuit-breakers are not entirely satisfactory for air-blast breakers. Among several minor changes it is necessary to add a test duty to prove that the breaker adequately limits switching over-voltages. The switching overvoltage which is most convenient to produce on test plants is that due to current-chopping in an inductive circuit. The voltage-limiting effect of the breaker can be demonstrated by taking a series of breaking tests at a current at which multiple current-chopping occurs. A duty comprising only three tests is considered inadequate to demonstrate the capability of the breaker to limit over-voltages, and it is suggested that twenty tests should be included. These should be sufficient to take care both of the variations in arc length at final interruption and also the statistical nature of the breakdown of air-gaps under rapidly applied voltages. 